\title{
Frequency of mitochondrial DNA point mutations among patients with familial sensorineural hearing impairment
}

\author{
Mervi S Lehtonen ${ }^{1,2}$, Seija Uimonen ${ }^{3}$, IImo E Hassinen ${ }^{2}$ and Kari Majamaa ${ }^{1,2}$ \\ Departments of ${ }^{1} \mathrm{~N}$ eurology, ${ }^{2} \mathrm{M}$ edical Biochemistry and ${ }^{3}$ Otorhinolaryngology, University of Oulu, Oulu, Finland
}

\begin{abstract}
Several point mutations in mitochondrial DNA (mtDNA) have been shown to cause sensorineural hearing impairment (SNHI), but the frequency of these mutations among patients is not known. We identified 117 patients with possible matrilineal SNHI from population-based registers and found the 3243A $>\mathrm{G}$ mutation to be present in $4.3 \%$ and $1555 A>G$ in $2.6 \%$, while $7445 T>C, 7472$ ins $C$ and $8344 A>G$ were absent. Patients with 3243A > G and 1555A > G were clinically distinct. The prevalence of 1555A $>G$ in the general adult population was estimated to be at least $4.7 / 100000$, but these and previous data suggest that the figure may vary between populations. Screening for mtDNA mutations is worthwhile in connection with the diagnosis of SNHI. European Journal of Human Genetics (2000) 8, 315-318.
\end{abstract}

Keywords: genetic epidemiology; mitochondrial encephalomyopathy; etiology; population genetics; MELAS; aminoglycoside; point mutation; prevalence; hereditary hearing loss

\section{Introduction}

Sensorineural hearing impairment $(\mathrm{SNHI})$ is a common phenotype in diseases caused by mutations in mitochondrial DNA (mtDNA), ${ }^{1,2}$ but among unselected patients with SNHI mtDNA mutations have been considered to be rare. We have found 3243A $>$ G, the mutation causing the MELAS syndrome, at a minimum frequency of $16 / 100000$ in one population, ${ }^{3}$ suggesting that it may also be a significant etiological factor for hearing impairment. In addition, mtDNA mutations have been detected among patients with nonsyndromic hearing impairment. The mutation 1555A > G was the first to be identified, ${ }^{4}$ and interestingly, it also appears to confer an increased risk of hearing impairment in conjunction with the use of aminoglycosides. ${ }^{4}$ The mutations 7445A $>\mathrm{A}$ and 7472insC have been reported only in selected families ${ }^{5-7}$ and $1555 \mathrm{~A}>\mathrm{G}$ in small series of cases $^{4,8,9}$ except for a recent study, where a very high frequency of 1555A > G has been observed among Spanish families with maternally inherited sensorineural hearing impairment. ${ }^{10}$

Correspondence: Dr Kari Majamaa, MD, University of Oulu, Department of Neurology, PO Box 5000, FIN-90401 Oulu, Finland. Tel:

+3588315 4526; Fax: +35883154544; E-mail: kari.majamaa@oulu.fi

Received 25 May 1999; revised 19 October 1999; accepted

25 November 1999
In order to study the prevalence of these mtDNA mutations among patients with $\mathrm{SNHI}$ we identified cases by reviewing registers at the audiological units serving a specific population and collected cases that fulfilled certain criteria including family history data. In this population-based cohort of patients we estimated the frequencies of the pathogenic point mutations in mtDNA known to be causal for SNHI.

\section{Materials and methods}

\section{Ascertainment of the patient cohort}

The prevalence area considered here is northern Finland, the provinces of Oulu and Lapland, excluding six local government districts in the province of Lapland. The total population of the area on the prevalence date 31 December 1994, was 579991, and people aged 20 years old or more numbered 409206. The Departments of Otorhinolaryngology at Oulu University Hospital and the Central Hospitals of Lapland and Kainuu are the only centres in northern Finland providing audiological services. The files kept on patients who have received a hearing aid are therefore representative of the prevalence of moderate, severe and profound hearing impairment in the population. To ascertain the patient cohort, the registers of hearing aids supplied to patients were reviewed at the three otorhinolaryngological units (Table1). 
Table 1 Identification of patients with matrilineal SNHI

\begin{tabular}{|c|c|c|c|c|c|c|}
\hline Population & $\begin{array}{l}\text { Total on } \\
\text { register } \\
\mathrm{n}\end{array}$ & $\begin{array}{l}\text { Patients fulfilling } \\
\text { selection criterion } \\
n\end{array}$ & $\begin{array}{l}\text { Response to family } \\
\text { history questionnaire } \\
\mathrm{n}\end{array}$ & $\begin{array}{l}\text { Cases identified } \\
\mathrm{n}\end{array}$ & $\begin{array}{l}\text { Samples obtained } \\
\mathrm{n}\end{array}$ & $\%$ \\
\hline Northern Ostrobothnia & 6839 & 242 & 178 & 108 & 82 & 79 \\
\hline Kainuu & 1558 & 82 & 59 & 30 & 23 & 77 \\
\hline Lapland & 2245 & 96 & 63 & 34 & 25 & 74 \\
\hline Total & 10642 & 420 & 300 & 172 & 133 & 77 \\
\hline
\end{tabular}

There is universal access to health care in Finland and the inhabitants are assigned to publicly funded health services on a regional basis. The cost of hearing aids is completely refunded by the public health service and, in the prevalence area, they are supplied only by the Departments of Otorhinolaryngology at Oulu University Hospital or at the Central Hospitals of Kainuu and Lapland. The registers of hearing aids supplied were reviewed using the following clinical criteria: symmetric sensorineural hearing impairment with pure tone average (PTA $0.5-2 \mathrm{kHz}$, defined as the mean hearing threshold at the frequencies of $0.5,1$ and $2 \mathrm{kHz}$ ) $>30 \mathrm{~dB}$, a difference $\leq 10 \mathrm{~dB}$ between the ears, undefined etiology, and the use of a hearing aid before age 45 . The family history with respect to hearing impairment in first and second degree relatives was then assessed by means of a questionnaire and patients with possible maternal inheritance were recruited. Maternal inheritance was considered possible when hearing impairment was reported in at least one maternal relative.

The study protocol was approved by the Ethics Committee of the Medical Faculty, University of Oulu. Permission for the chart review was obtained from the Ministry of Social Affairs and Health. The samples were studied after obtaining informed consent from the patients.

\section{Molecular methods}

Template DNA from blood, buccal epithelial cell samples or muscle was amplified in a PCR reaction in 30 cycles and the amplified fragments were screened for the mutations $1555 \mathrm{~A}>\mathrm{G}, 3243 \mathrm{~A}>\mathrm{G}, 7445 \mathrm{~T}>\mathrm{C}, 7472$ insC and 8344A > G by a restriction fragment analysis. ${ }^{4,6,11-13}$ The digested samples were electrophoresed through a 1.5\% agarose, 3\% MetaPhor agarose (FMC BioProducts, Rockland, ME, USA) or $6 \%$ nondenaturating polyacrylamide gel, as appropriate. Mitochondrial DNA haplogroups were determined by restriction fragment length polymorphisms. ${ }^{14}$

\section{Clinical evaluation}

Members of a family with $1555 \mathrm{~A}>\mathrm{G}$ (Figure1) and in five families with $3243 A>G$ were examined otorhinolaryngologically. Audiograms were used to calculate PTA $\mathrm{A}_{0.5-2 \mathrm{kHz}}$.

\section{Results \\ Frequency of mtDNA point mutations known to be associated with SNHI}

We obtained samples from 133 patients with SNHI, reportedly representing 117 separate maternal lineages (Table 1 ). We found five patients with the 3243A $>G$ mutation and three patients with the $1555 \mathrm{~A}>\mathrm{G}$ mutation in the cohort, whereas the mutations 7445A > G, 7472insC and 8344A > G were absent. The frequencies of the mutations in the cohort were thus $4.3 \%$ for $3243 \mathrm{~A}>\mathrm{G}$ and $2.6 \%$ for $1555 \mathrm{~A}>\mathrm{G}$, suggesting a total frequency of mtDNA mutations known to be associated with hearing impairment of $6.9 \%$.

The probands with 1555A > G were from two families. The mutation was verified in all 22 members of one family, representing three generations (Figure1), whereas only the proband could be studied in the other. We identified 14 members in these families with the mutation and 13 who were first degree maternal relatives of a verified carrier and were living in the prevalence area. Combining these figures, we estimated that the minimum prevalence of 1555A > G in this population was thus $4.7 / 100000$.

Restriction fragment analysis of mtDNA and sequencing of the mtDNA D-loop revealed that one of the families with

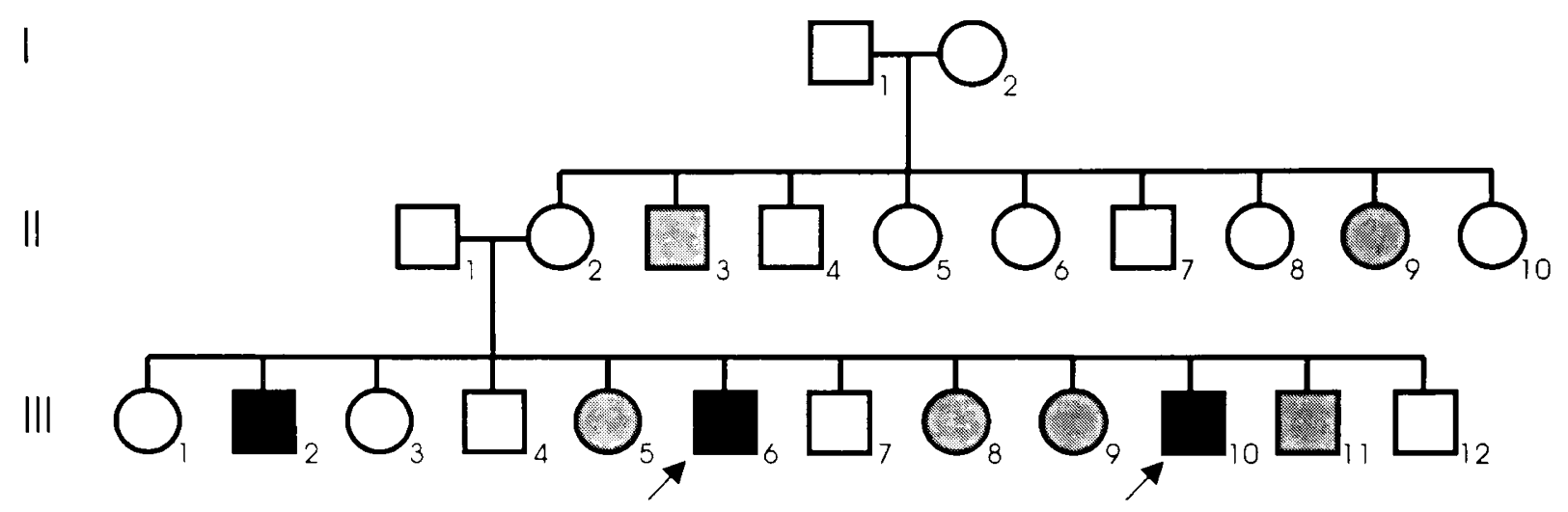

Figure 1 Pedigree of Family A, with 1555A > G. Solid symbols: profound hearing impairment; grey symbols: hearing impairment at high frequencies; open symbols: normal hearing. Arrows indicate the two probands identified in the cohort. 
1555A > G belonged to mtDNA haplogroup J (Family A) and the other to haplogroup $\mathrm{H}$ (Family B). Three of the probands with $3243 \mathrm{~A}>\mathrm{G}$ belonged to mtDNA haplogroup $U$ and two to haplogroup $\mathrm{H}$.

\section{Audiological evaluation of Family $A$ and the families with 3243A > G}

Audiometry was performed on the 22 members of Family $A$ (Figure 1 ) and on 14 members harbouring 3243A $>\mathrm{G}$ in the five pedigrees. The two probands in Family $A$ and one of their brothers had a profound hearing impairment that had been diagnosed earlier, between the ages of 4 and 5 years, whereas only one person with $3243 \mathrm{~A}>\mathrm{G}$ was similarly affected (Figure2). Moderate hearing impairment was found in most patients with $3243 A>G$, whereas most of the members in Family A had normal hearing or had a hearing impairment only at high frequencies.

\section{Discussion}

We obtained a combined frequency of $6.9 \%$ for the mtDNA mutations $3243 \mathrm{~A}>\mathrm{G}$ and $1555 \mathrm{~A}>\mathrm{G}$ among patients with possible matrilineal SNHI. Extrapolation of the observed counts furthermore suggested that the two mutations may be found at a frequency of 7.5/10000 among unselected patients using a hearing aid. The $3243 \mathrm{~A}>\mathrm{G}$ mutation was found at a frequency of $4.3 \%$, whereas an average frequency of $2 \%$ has been reported among patients with familial diabetes mellitus. ${ }^{15}$ Furthermore, we estimated the minimum population prevalence of $1555 \mathrm{~A}>\mathrm{G}$ to be $4.7 / 100000$ in northern
Finland. This rate was obtained partly from the same population as the prevalence of $16.3 / 100000$ for the 3243A > G mutation. ${ }^{3}$ These data suggest that mtDNA mutations are not uncommon in population.

We found $1555 \mathrm{~A}>\mathrm{G}$ at a frequency of $2.6 \%$ in the cohort, and the fact that only case reports have previously been published on this mutation likewise suggests that it is rare among patients with SNHI. ${ }^{4,8,9}$ In contrast, every patient with matrilineal hearing impairment in a Spanish cohort was found to harbour $1555 \mathrm{~A}>\mathrm{G} .{ }^{10}$ The discrepancy in the observed frequencies may be explained by several factors. Firstly, ascertainment bias may be involved, ${ }^{16}$ as our results are based on patients detected in population-based registers, while the patients reported by Estivill et $\mathrm{al}^{10}$ were selected from several clinical centres or were obtained through advertisements in the public media. Secondly, a founder effect has been shown to explain the high prevalence of $1555 A>G$ in a Zairrean village, ${ }^{17}$ but its contribution is difficult to assess in the Spanish cohort of 19 families. MtDNA haplotypes were determined in only 10 families, six of which belonged to a specific haplotype within mtDNA haplogroup $\mathrm{H} .{ }^{10}$ Thirdly, aminoglycosides have been shown to predispose patients with $1555 \mathrm{~A}>\mathrm{G}$ to hearing impairment. ${ }^{4}$ Quite interestingly, the sales volume of aminoglycosides per capita was 25-fold higher in Spain than in Finland in 1998 (data from IMS Health, Helsinki, Finland) suggesting that differences in the use of these antibiotics in the two countries may explain the observed mutation frequencies. Fourthly, however, there may be true differences in the frequency of the mutation between the populations. This

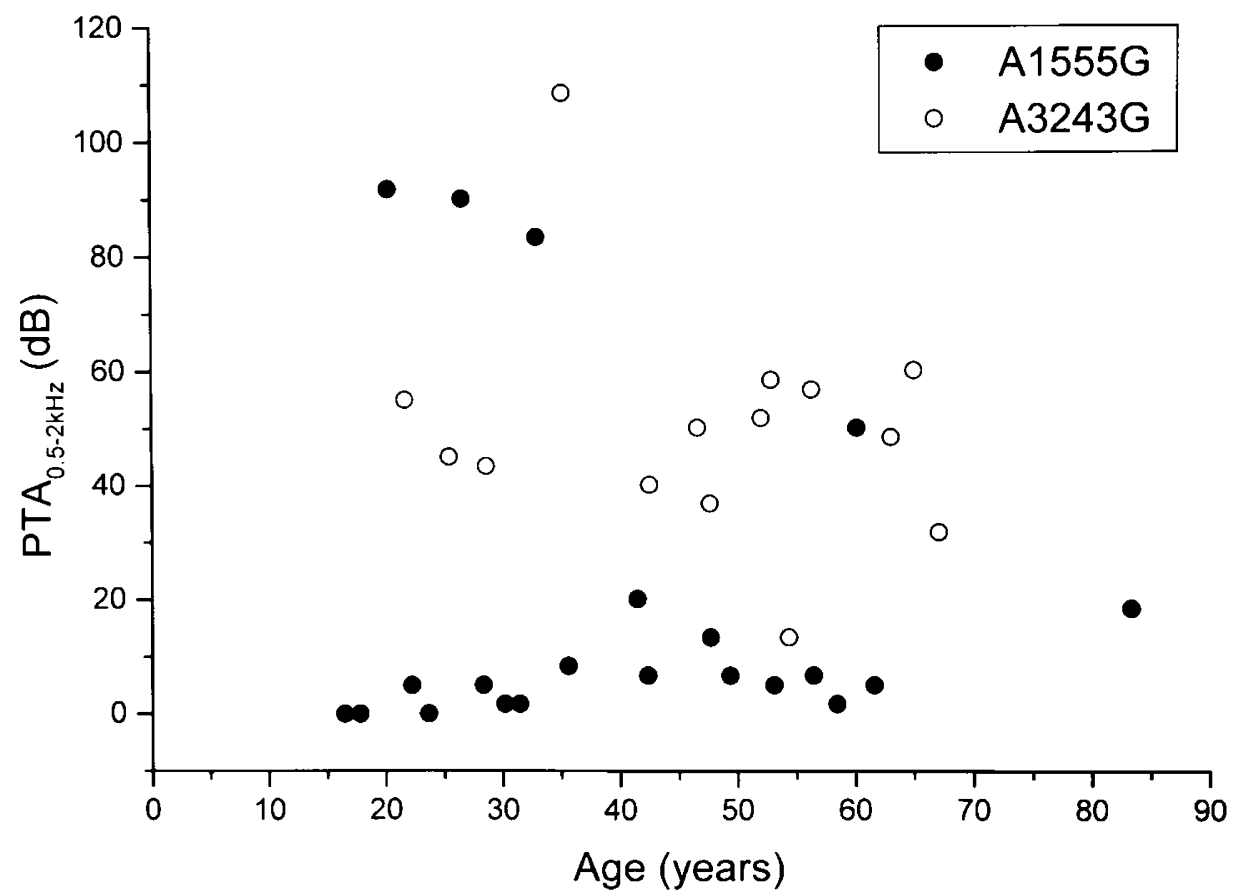

Figure 2 Pure tone average $\left(\mathrm{PTA}_{0.5-2 \mathrm{kHz}}\right)$ as a function of age in members of Family A and of the families with $3243 \mathrm{~A}>\mathrm{G}$. 
would imply that the frequency of pathogenic mutations in population is determined not only by genetic drifting and selection but by factors affecting the genesis and fixation of new mutations, or that the phenotypic expression of a mutation may differ between populations.

Audiological evaluation of the members of Family $A$ revealed differences in the severity of $\mathrm{SNHI}$, as half of the family members had normal hearing suggesting that 1555A > G may not cause hearing loss by itself. None of the members in Family A had a history of aminoglycoside use, whereas a chart review verified definite history of aminoglycoside induced hearing impairment in the case of the proband in Family B. Other environmental or genetic factors may have been involved in the case of Family A. Interestingly, three phenotypes of hearing impairment were found in this family and their segregation was compatible with the hypothesis that the pathogenicity of the mtDNA mutation is influenced by an autosomal recessive factor.

We found a substantial frequency of pathogenic mtDNA mutations among patients with matrilineal SNHI suggesting that screening of these patients for $3243 A>G$ and $1555 A>G$ at least is worthwhile. Specifically, the diagnosis of $1555 \mathrm{~A}>\mathrm{G}$ may help to prevent accidental aminoglycoside-induced hearing loss. Furthermore, these and other data suggest that the differences in the observed frequency of $1555 \mathrm{~A}>\mathrm{G}$ may be attributed to different volumes of aminoglycoside use or to true differences in the prevalence of the mutation.

\section{Acknowledgements}

The expert technical assistance of Ms Anja Heikkinen is acknowledged. This work was supported in part by grants from the M edical Research Council of the Academy of Finland and the Sigrid Juselius Foundation.

\section{References}

1 Johns DR: Mitochondrial DNA and disease. N Engl J Med 1995; 333: 638-644.

2 Chinnery PF, Howell N, Lightowlers RN, Turnbull DM: Molecular pathology of MELAS and MERRF. The relationship between mutation load and clinical phenotypes. Brain 1997; 120: 1713-1721.
3 Majamaa K, Moilanen JS, Uimonen Set al: Prevalence, in an adult population, a A3243G, the mutation for mitochondrial encephalomyopathy, lactic acidosis and strokelike episodes. Am J Hum Genet 1998; 63: 447-454.

4 Prezant TR, Agapian JV, Bohlman MC et al: Mitochondrial ribosomal RNA mutation associated with both antibiotic-induced and non-syndromic deafness. Nat Genet 1993; 4: 289-294.

5 Reid FM, Vernham GA, Jacobs HT: A novel mitochondrial point mutation in a maternal pedigree with sensorineural deafness. Hum Mutat 1994; 3: 243-247.

6 Tiranti V, Chariot P, Carella F et al: Maternally inherited hearing loss, ataxia and myoclonus associated with a novel point mutation in mitochondrial tRNA ${ }^{\text {Ser(UCN) }}$ gene. Hum Mol Genet 1995; 4: 1421-1427.

7 Ensink RJH, Verhoeven MSc, Marres HAM et al: Early-onset sensorineural hearing loss and late onset neurologic complaints caused by a mitochondrial mutation at position 7472. Arch Otolaryngol 1998; 124: 886-891.

8 Usami S, Abe S, Kasai M et al: Genetic and clinical features of sensorineural hearing loss associated with the 1555 mitochondrial mutation. Laryngoscope 1997; 107: 483-490.

9 El-Schahawi M, López de Munain A, Sarrazin AM et al: Two large Spanish pedigrees with nonsyndromic sensorineural deafness and the mtDNA mutation at nt 1555 in the $12 \mathrm{~S}$ rRNA gene: evidence of heteroplasmy. Neurology 1997; 48: 453-456.

10 Estivill X, Govea N, Barceló A et al: Familial progressive sensorineural deafness is mainly due to the mtDNA A1555G mutation and is enhanced by treatment with aminoglycosides. Am J Hum Genet 1998; 62: 27-35.

11 Kobayashi $\mathrm{Y}$, Momoi MY, Tominaga $\mathrm{K}$ et al: A point mutation in the mitochondrial tRNA ${ }^{\text {Leu(UUR) }}$ gene in MELAS (mitochondrial myopathy, encephalopathy, lactic acidosis and strokelike episodes). Biochem Biophys Res Commun 1990; 173: 816-822.

12 Fischel-Ghodsian N, Prezant TR, Fournier P, Stewart IA, Maw M: Mitochondrial mutation associated with nonsyndromic deafness. Am J Otolaryngol 1995; 16: 403-408.

13 Zeviani $\mathrm{M}$, Amati $\mathrm{P}$, Bresolin $\mathrm{N}$ et al: Rapid detection of the $A \rightarrow G(8344)$ mutation of mtDNA in Italian families with myoclonus epilepsy and ragged-red fibers (MERRF). Am J Hum Genet 1991; 48: 203-211.

14 Torroni A, Huoponen K, Francalacci $P$ et al: Classification of European mtDNAs from an analysis of three European populations. Genetics 1996; 144: 1835-1850.

15 van den Ouweland JM, Lemkes HH, Gerbitz KD, Maassen JA: Maternally inherited diabetes and deafness (MIDD): a distinct subtype of diabetes associated with a mitochondrial tRNA ${ }^{\text {LeuUUR }}$ gene point mutation. Muscle Nerve 1995; 3: 124-130.

16 Susser E, Susser M: Familial aggregation studies. A note on their epidemiological properties. Am J Epidem 1989; 129: 23-30.

17 Matthijs G, Claes S, Longo-Mbenza B, Cassiman J-J: Nonsyndromic deafness associated with a mutation and a polymorphism in the mitochondrial $12 \mathrm{~S}$ ribosomal RNA gene in a large zairean pedigree. Eur J Hum Genet 1996; 4: 46-51. 